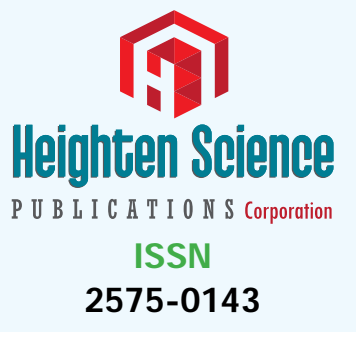

*Address for Correspondence: Dioum M Cardiology Clinic of CHU Fann, Cheikh Anta Diop University, Hospital FANN-BP 5534-Dakar, Senegal, Tel: 221776551883; E-mail: momar.dioum@yahoo.fr

Submitted: 15 December 2016

Approved: 16 February 2017

Published: 20 February 2017

Copyright: @ 2017 Dioum M, et al. This is an open access article distributed under the Creative Commons Attribution License, which permits unrestricted use, distribution, and reproduction in any medium, provided the original work is properly cited

\section{Short and Medium-Term Evaluation of Patients in Coronary Post-Angioplasty: Préliminary results at the Cardiology Department of the Hospital University Aristide Le Dantec of Dakar (Senegal): Study on 38 Cases}

\author{
Dioum Mi*, Aw F², Masmoudi K², Gaye ND², Sarr SA², Ndao \\ $\mathrm{SCT}^{2}$, Mingou J ${ }^{2}$, Ngaidé $\mathrm{AA}^{3}$, Diack $\mathrm{B}^{3}$, Bodian $\mathrm{M}^{2}$, Ndiaye \\ $\mathrm{MB}^{2}$, Diao $\mathrm{M}^{2}$ and $\mathrm{Ba} \mathrm{SA}^{2}$ \\ ${ }^{1}$ FANN Hospital, Cardiology Department. Faculty of Medicine, Cheikh Anta Diop University of \\ Dakar, Senegal \\ ${ }^{2}$ Cardiology Department of Aristide Le Dantec Hospital. Faculty of Medicine, Cheikh Anta Diop \\ University of Dakar, Senegal \\ ${ }^{3}$ Cardiology Department of Grand Yoff General Hospital. Faculty of Medicine, Cheikh Anta Diop \\ University of Dakar, Senegal
}

\section{ABSTRACT}

Introduction: Coronary angioplasty is a safe therapeutic method for coronary disease. However, its major obstacles remain the occurrence of stent thrombosis (ST) and in-stent restenosis (ISR). The aim of this study was to evaluate the short-term and medium-term results of coronary angioplasty patients in the cardiology department of Aristide Le Dantec hospital in Dakar.

Methodology: It was a longitudinal, descriptive and analytical study over a period of 12 months (April 2014 to April 2015) with a follow-up at 6 months. Was included any patient who had a coronary angioplasty with stent placement.

Results: Thirty-eight patients had been included with a male predominance and a sex ratio of 5.32. The average age was 57.94 years. Cardiovascular risk factors were mainly smoking (57.9\%) and coronary heredity (42.1\%), followed by hypertension (39.5\%) and diabete $(34.2 \%)$. The indications for angioplasty were acute coronary syndromes TS(+) and TS(-) respectively (50\%) and (23.7\%) and stable angina (26.3\%). The right femoral approach was almost exclusive (97.4\%). Coronary angiography revealed a predominance of anterior interventricular affection (84.2\%). Type B lesions were the most frequent (68.4\%). The single-truncal valve affection was predominant (76.3\%). Direct stenting accounted for $63.2 \%$ of procedures. Twenty-one bare stents $(55.3 \%)$ and 17 active stents (44.7\%) were implanted. The results were excellent (94.7\%). One case of acute stent thrombosis was noted. Echocardiography of dobutamine stress during follow-up was positive in 04 patients (12.5\%). The control coronary angiography performed in two patients revealed an ISR. The predictive factors for restenosis were dominated by a deterioration in the segmental kinetics $(p=0.009)$, in the diastolic function ( $p=0.002)$, the systolic function $(p=0.003)$, a high post angioplasty troponin $(p=0.004)$, the presence of calcifications $(p=0.004)$ and a high SYNTAX score $(p=0.021)$.

Conclusion: According to these results, Angioplasty is an effective therapy for coronary disease. However, a correct intake of double platelet antiaggregants and clinical and non-invasive screening are required for follow-up to avoid stent thrombosis or restenosis. 


\section{INTRODUCTION}

Cardiovascular diseases are the leading cause of death in developed countries [1]. In developing countries, this mortality represents $86 \%$ of deaths [2]. Coronary heart diseases are an important part of cardiovascular diseases. According to WHO, they are responsible for nearly 7 million deaths per year, or $12.8 \%$ of global mortality in 2012 [1]. Its management has seen spectacular advances with the advent of coronary angioplasty [3]. Continually relying on both technical and pharmacological improvements, it rapidly became a safe therapeutic whose indications are constantly expanding. The main limitations are stent thrombosis (ST) and, mainly, in-stent restenosis (ISR), which is currently a real "Achilles tendon" that angioplasty is constantly overcoming thanks to the improvement of the endoprostheses and in particular to the development of active stents [4]. Numerous scientific studies have identified the predictive factors of ISR: diabetes, the size of the treated artery, the location and length of the lesion, the usage or not of a predilatation, the degree of residual stenosis in immediate post angioplasty, etc. [5-7]. This led us to conduct this study whose objective was to evaluate the shortand medium-term results of patients in post-coronary angioplasty in the cardiology department of Aristide Le Dantec hospital in Dakar, in order to detect possible ST or ISR.

\section{METHODOLOGY}

It was a longitudinal, descriptive and analytical study covering a period of 12 months (April 2014 to April 2015) with a follow-up at 6 months. All patients who had received transluminal coronary angioplasty were included with the implantation of stents in the interventional cardiology department of Aristide Le Dantec hospital in Dakar. Clinical, paraclinical, angiographic and post-angioplasty follow-up data were collected on preestablished data sheets. The post-angioplasty evaluation of the patients was done clinically, electrocardiographically and thanks to doppler ultrasonography during rest and during stress due to dobutamine. Control coronary angiography was proposed for patients with symptoms of recurrent ischemic at rest and/or exercise, as well as for those whose stress tests had been questionable or positive. The data had been entered with Excel 2007. Data analysis was carried out with the SPSS software version 20.

\section{RESULTS}

During the study period, 179 patients had been examined by coronary angiography. Thirty eight patients $(21.2 \%)$ had angioplasty. The masculine gender predominated with 32 men (84.2\%) and 6 women (15.8\%), including a sex ratio of 5.32. The average age was 57.94 y/o (39-89 y/o). The preponderant age group was > 55 (63.1\%). In addition to age, cardiovascular risk factors were dominated by active smoking (57.9\%) and coronary heredity (42.1\%), followed by hypertension (39.5\%) and diabetes Type II (34.2\%). Almost all patients (97.3\%) were polyfactorial. The indications for angioplasty were acute coronary syndromes TS(+) and TS(-) respectively 50\% and $23.7 \%$, and stable angina $26.3 \%$. Thoracic pain was the major symptom (31.6\%). At the electrocardiography, abnormalities of ischemic-epicardial lesion-type repolarization were noticed (36.8\%) with predominance of anterior region $(55.2 \%)$. The cardiac Doppler echo returned to an average left ventricular ejection fraction (LVEF) at $48.5 \%$ [27-77\%]. Systolic dysfunction was observed in 18 patients. Hypokinesia was the most frequent kinetic disorder. "Delayed or late" angioplasty was performed during the period of hospitalization in $73.6 \%$ of cases. The remaining patients (26.4\%) had programmed angioplasty. No primary angioplasty or rescue angioplasty was performed in patients with TS(+). The right femoral approach was almost exclusive (97.4\%). Only one patient 
had a right radial approach. Coronary angiography revealed a predominance of anterior interventricular affection (84.2\%), followed by the affection of the circumflex-marginal network (23.6\%).

Type B lesions were the most frequent: B1=31.6\% and B2=36.8\%. Three patients had C-type lesions. Single-truncal affection was predominant (76.3\%). Multi-truncular lesions included two-truncular ones (21.1\%) and tri-truncular ones (01 patients). The SYNTAX score varied between 2 and 28 with an average value of 8.9. A balloon pre-dilation was carried out in $36.8 \%$ of the cases. Direct stenting concerned $63.2 \%$ of procedures. Twenty-one bare stents (55.3\%) and 17 active stents (44.7\%) were implanted. The average number of stents per patient was 1.18 . The average diameter of the stents was 3.25 and the average length was $17.4 \mathrm{~mm}$. The results were excellent in $94.7 \%$ of cases with a TIMI grade 3 flow and without dissection. The average hospital stay in post-angioplasty was 2.31 days [01-08 days]. Intra-hospital progression was favorable in 35 of our patients (92.1\%). Two early deaths during the first 48 hours were recorded. One case of acute stent thrombosis was noted 24 hours after angioplasty. At 2 and 6 months, two cases of angina due to exercise and three cases of dyspnea stage II-III of the NYHA were noted clinically. Electrical abnormalities were mainly related to changes in the ST segment with epicardial ischemia. Nevertheless, a third death occurred following a probable angina attack less than 2 months post ATL. Echocardiography of dobutamine stress during follow-up was positive in 04 patients (12.5\%). Control coronary angiography performed in two patients revealed very tight in-stent restenosis (Figure 1). The predictive factors for restenosis were dominated by a deterioration of the segmental kinetics $(p=0.009)$, the diastolic function $(p=0.002)$, the systolic function $(p=0.003)$, a high post angioplasty troponin $(p=0.004)$, the presence of calcifications $(p=0.004)$ and a high SYNTAX score $\geq(p=0.021)$ (Table 1$)$.

\section{DISCUSSION}

Intra-hospital evolution was favorable in the majority of cases (92.1\%). However, one acute stent thrombosis and two early deaths during the first 48 hours following angioplasty, probably due to a ST were noted. Predictive factors for intra-hospital mortality were similar to those in the literature, ie, advanced age and the presence of complex and proximal coronary lesions [8-10]. These factors corresponded to our deaths cases. At short-term control, a third death occurred. The hypothesis of late stent thrombosis or short-term ISR is more likely. The FAST-MI 2005 [11] and RESCUE 2008-2009 [12] registers have a 30-day mortality rate comparable to our series, of 7\%

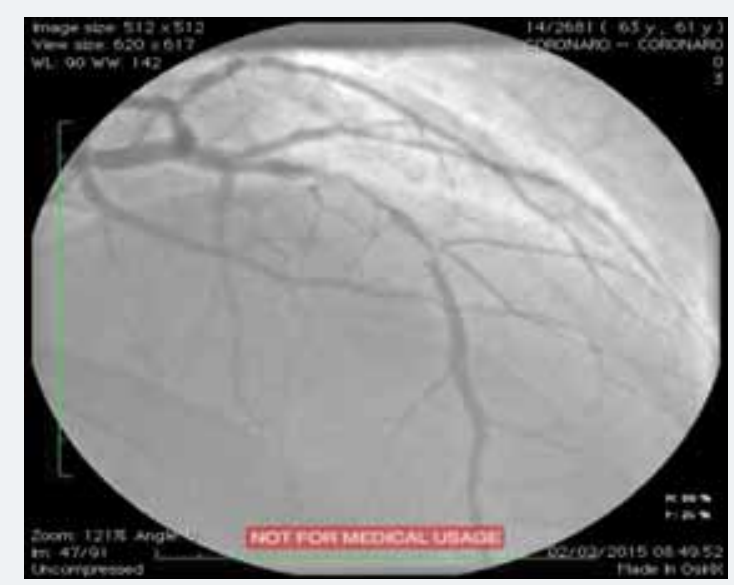

Figure 1: Drug-eluting in-stent restenosis of left anterior descending coronary artery in a patient with a positive stress echocardiography.. 


\begin{tabular}{|c|c|c|c|}
\hline \multicolumn{1}{|c|}{ Fable 1: Summary of predictive factors of in-stent restenosis (ISR). } & & \\
\hline Diagnosis of stable coronary artery disease & Odds ratio (OR) & Confidence interval & P-value \\
\hline Lack of regular physical exercise & 6,0 & {$[1,1-30,6]$} & 0,036 \\
\hline Dyspnoea stage $\geq$ II (NYHA) in the medium term & 5,0 & {$[0,9-26,9]$} & 0,049 \\
\hline Assessment of troponin I after PCI > baseline value & 14,0 & {$[1,2-158,8]$} & 0,019 \\
\hline Deterioration of segmental wall-motion in the short term & 5,1 & {$[1,8-64]$} & 0,004 \\
\hline Deterioration of diastolic function in the short term & 5,1 & {$[2,6-9,9]$} & 0,009 \\
\hline Deterioration of diastolic & 5,1 & {$[2,6-9,9]$} & 0,009 \\
\hline function in the medium term & {$[2,6-9,9]$} & 0,002 \\
\hline Deterioration of systolic function in the medium term & 5,1 & {$[2,6-9,9]$} & 0,003 \\
\hline Presence of calcifications & 18,4 & {$[1,8-64]$} & 0,004 \\
\hline SYNTAX score $\geq 23$ (intermediate / high) & 6,9 & {$[1,1-40,9]$} & 0,021 \\
\hline Lenght of stent $\geq 15$ mm & 6,9 & {$[5,4-8,8]$} & 0,05 \\
\hline PCI : primary coronary intervention. & & \\
\hline
\end{tabular}

and 6\%, respectively (the rate found in our study being 7.8\%). In the medium term (6 months post-angioplasty), it is recommended to seek the reappearance of myocardial ischemia, silent or not, suspecting an in-stent restenosis [13]. This research can be done by a "stress test" to physical or chemical stimulation. In our study, mid-term evaluation included dobutamine stress echocardiography as indicated by recent recommendations in pauci-symptomatic patients as asymptomatic in the medium-term post ATL (Class I level of evidence A) $[13,14]$. This test was performed in our series between the 5 th and 11 th month post ATL in $84.2 \%$ of our entire sample. At the end of the examination, 04 cases were positive. Two patients had control coronary angiography that showed a very tight ISR ( $>90 \%$ ) and a TIMI grade 1 flow. The ISR predictive factors found in our patients are comparable to the data found in the BENESTENT $[15,16]$ and Cutlip et al. [17] studies. These predictors of restenosis were dominated by a deterioration of segmental kinetics, diastolic function, systolic function, high post angioplasty troponin, presence of calcifications and a high SYNTAX score.

\section{CONCLUSION}

According to these results, angioplasty is an effective therapy for coronary disease. However, a correct intake of both platelet antiaggregation and clinical and non-invasive screening are required for follow-up to avoid stent thrombosis or restenosis.

\section{LIMITS}

\section{Our study has some limitations:}

- The activity of interventional cardiology started 3 years ago In sub- Saharan Africa.

- The average number of patients included due to the high cost (100 dollars) of stress echocardiography and its availability. Also we have just acquired a cardiac ultrasound machine with stress software.

\section{REFERENCES}

1. WHO. The top 10 causes of death. 2013; Cité 30. Disponible sur: Ref.: https://goo.gl/bLfjF2

2. Maboury Diao, Serigne Abdou B. Maladies cardio-vasculaires et complications. CHU le Dantecm, Dakar-Sénégal 2013. Ref.: https://goo.gl/KgXNvJ

3. Philippe $F$, Dibie $A$, Larrazet $F$, Meziane $T$, Folliguet $T$ et al. Les stents à élution de médicaments: preuves, incertitudes et pratiques. Ann Cardiol Angéiol. 2005; 54: 201-211. Ref.: https://goo.gl/ascnp5

4. Chevalier B, Blanchard D, Berland J, Carrié D, Gilard M et al. Endoprothèses actives: Indications, limites et développements. Arch Mal Coeur Vaiss. 2005; 98: 1013-1021. Ref.: https://goo.gl/CuHW2 
5. Bauters C, Hubert E, Prat A, Bougrimi K, Van Belle EA, et al. Predictors of restenosis after coronary stent implantation. J Am Coll Cardiol. 1998; 31: 1291-1298. Ref.: https://goo.gl/smViit

6. Serruys PW, Kay IP, Disco C, Deshpande NV, de Feyter PJ. Periprocedural quantitative coronary angiography after Palmaz-Schatz stent implantation predicts the restenosis rate at six months: results of a meta-analysis of the BElgian NEtherlands Stent study (BENESTENT) I, BENESTENT I Pilot, BENESTENT II and MUSIC trials. Multicenter Ultrasound Stent In Coronaries. J Am Coll Cardiol. 1999; 34: 1067-1074. Ref.: https://goo.gl/8YghtL

7. Schiele F. Predictive factors of restenosis: what changes with "active" stents? Pathology Biology. 2004; 52: 206-211. Ref.: https://goo.gl/RAkuK4

8. Zouaoui W, Ouldzein H, Boudou N, Dumonteil N, Bongard V, et al. Factors predictive for in-hospital mortality following percutaneous coronary intervention. Arch Cardiovasc Dis. 2008; 101: 443-448. Ref.: https://goo.gl/MxVZQH

9. Wilensky RL, Selzer F, Johnston J, Laskey WK, Klugherz BD, et al. Relation of percutaneous coronary intervention of complex lesions to clinical outcomes (from the NHLBI Dynamic Registry). Am J Cardiol. 2002; 90: 216-221. Ref.: https://goo.gl/XDUHkh

10.Assali AR, Moustapha A, Sdringola S, Salloum J, Awadalla $H$ et al. The dilemma of success: percutaneous coronary interventions in patients $>$ or $=75$ years of age-successful but associated with higher vascular complications and cardiac mortality. Catheter Cardiovasc Interv. 2003; 59: 195199. Ref.: https://goo.gl/3wtkA1

11.Cambou JP, Simon T, Mulak G, Bataille V, Danchin N. The French Registry of Acute ST Elevation or Non-ST-Elevation Myocardial Infarction (FAST-MI): study design and baseline characteristics. Arch Mal Coeur Vaiss. 2007; 100: 524-534. Ref.: https://goo.gl/yHc6nN

12. Ko DT, Atzema CL, Donovan LR, Graham MM, Huynh T. Rescue Percutaneous Coronary Interventions for Failed Fibrinolytic Therapy in ST-segment Elevation Myocardial Infarction. Am Heart J. 2011; 161: 764-770. Ref.: https://goo.gl/46D3YW

13.Authors/Task Force members, Windecker S, Kolh P, Alfonso F, Collet JP, et al. 2014 ESC/EACTS Guidelines on myocardial revascularization: The Task Force on myocardial revascularization of the European Society of Cardiology (ESC), the European Association for Cardio-Thoracic Surgery (EACTS), European Association for Percutaneous Cardiovascular Interventions (EAPCI). Eur Heart J. 2010; 31: 2541-2619. Ref.: https://goo.gl/tfUL2t

14. Chevalier B. American recommendations on coronary angioplasty. Consensus Cardio. 2012; 78: 1-4.

15.Serruys PW, de Jaegere P, Kiemeneij F, Macaya C, Rutsch W, et al. A comparison of balloonexpandable-stent implantation with balloon angioplasty in patients with coronary artery disease. Benestent Study Group. N Eng J Med. 1994; 331: 489-495. Ref.: https://goo.gl/Mk8PT0

16.Serruys PW, van Hout B, Bonnier H, Legrand V, Garcia E, et al. Randomised comparison of implantation of heparin-coated stents with balloon angioplasty in selected patients with coronary artery disease (BENESTENT II). Lancet. 1998; 352: 673-681. Ref.: https://goo.gl/fWcRre

17.Cutlip DE, Chauhan MS, Baim DS, Ho KK, Popma JJ, et al. Clinical Restenosis After Coronary Stenting: Perspectives From Multicenter Clinical Trials. J Am Coll Cardiol. 2002; 40: 2082-2089. Ref.: |https://goo.gl/aOD490 